\title{
Retention and clearance of inhaled ceramic fibres in rat lungs and development of a dissolution model
}

\author{
Hiroshi Yamato, Hajime Hori, Isamu Tanaka, Toshiaki Higashi, Yasuo Morimoto, \\ Masamitsu Kido
}

\begin{abstract}
Male Wistar rats were exposed to aluminium silicate ceramic fibres by inhalation to study pulmonary deposition, clearance, and dissolution of the fibres. Rats were killed at one day, one month, three months, and six months after the termination of exposure. After exposure, fibres greater than $50 \mu \mathrm{m}$ in length were seen with a scanning electron microscope in the alveolar region of the lung. Fibres were recovered from the lungs with a low temperature ashing technique and their number, diameter, and length were measured by scanning electron microscopy. The number of fibres remaining in the lungs declined exponentially with time after exposure and their silicon content also fell. The geometric median diameter of fibres decreased linearly with time. By six months after exposure, the surface of fibres recovered from the lungs had an eroded appearance. The results suggest that ceramic fibres are physically cleared from the lung and that they show signs of dissolution. Finally, the results were used to develop a theoretical model of fibre dissolution that gives a satisfactory fit to the experimental data.
\end{abstract}

(Occup Environ Med 1994;51:275-280)

The physical dimensions, clearance, and biopersistence of fibres in the lungs are important factors in predicting their biological effects. To study the clearance of man made mineral fibres from the lung, a number of studies have been performed in which the fibres were given either by intratracheal injection $^{1-3}$ or by inhalation. ${ }^{45}$ It seems that man made mineral fibres given by these routes are cleared from the lung by transport to the conducting airways and by dissolution. Morgan et $a l^{1}$ and Holmes et $a l^{2}$ showed that short glass fibres were cleared efficiently by macrophage mediated processes but that fibres exceeding a critical length (between 10 and $30 \mu \mathrm{m}$ ) were not removed. Their results also suggested that the rate of dissolution of glass fibres depends on their length (long fibres dissolve more rapidly than short fibres) and animal species (glass fibres dissolved more rapidly in hamster than in rat lungs). The chemical composition of the fibre is also thought to be an important factor in determining the durability of fibres in the lung. Le Bouffant et al showed that those fibres that had remained for several months in the lung had an eroded appearance and the amounts of sodium, calcium, and magnesium were depleted. ${ }^{5}$ Leinweber studied the solubility of six types of man made mineral fibre in vitro and showed that the solubility of fibres varied over a wide range depending on their chemical composition. He also showed that dissolution rates could be calculated. ${ }^{6}$ The clearance of inhaled fibres has also been estimated by analysing the amount of a major component (for example, silicon) remaining in the lung. ${ }^{4}$ Morgan and Holmes ${ }^{7}$ reviewed the published works on the solubility of mineral fibres. There are few studies, however, that have measured all these variables after inhalation exposure and discussed them comprehensively.

In this study, we exposed rats to ceramic fibres by inhalation and determined changes in the number, length, diameter, and surface structure of fibres at various times. At the same time, we measured changes in the silicon content of lungs (silicon is the main component of the ceramic fibres). An attempt was made to model these findings mathematically.

\section{Materials and methods}

TEST SUBSTANCES

The aluminum silicate ceramic fibres used in this study were made by a Japanese manufacturer. The chemical composition of the fibre is $54 \% \mathrm{SiO}_{2}$ and $46 \% \mathrm{Al}_{2} \mathrm{O}_{3}$. To obtain respirable fibre particles having a mass median aerodynamic diameter of less than $5 \mu \mathrm{m}$, bulk ceramic fibres were disintegrated three times with an ultracentrifugal mill (Retch Co, Germany) at a speed of $15000 \mathrm{rpm}$.

\section{EXPOSURE SYSTEM}

Details of our system and apparatus have been reported in previous papers. ${ }^{8-12}$ To obtain a constant concentration, the ceramic fibres were mixed with fluidising particles (small glass beads with a diameter of $250 \mu \mathrm{m}$ ). The mixture was fed into a hopper and transported smoothly via a continuous screw feed into a fluidised bed. Dry air flowing upwards through the fluidised bed dispersed the ceramic fibres. Airflow was high enough to transport the ceramic fibres but not the fluidising particles to the exposure chamber.

\section{CONCENTRATION AND SIZE DISTRIBUTION IN} THE EXPOSURE CHAMBER

Each day during exposure the mass concentration of the ceramic fibres was measured 
gravimetrically by isokinetic sampling of chamber air through a glass filter. The average concentration was $27 \cdot 2$ (SD $9 \cdot 0) \mathrm{mg} / \mathrm{m}^{3}$. The size distribution of the aerosol in the exposure chamber was determined with an Andersen cascade impactor (Model AN-200, Sibata Sci Tech Ltd, Japan). The mass median aerodynamic diameter and the geometric standard deviation (GSD) of the ceramic fibres in the chamber were $3.7 \mu \mathrm{m}$ and $2 \cdot 2$ respectively. The geometric median length and the geometric median diameter of airborne fibres in the chamber were 20.0 (GSD 3.3$) \mu \mathrm{m}$ and 1.35 (GSD 1.8$) \mu \mathrm{m}$ respectively.

ANIMALS

Twenty male Wistar rats nine weeks old at the start of the experiment were used. They were exposed to ceramic fibres daily for six hours a day, five days a week, for two weeks. Groups were then killed at one day, one month, three months, and six months after the end of the exposure and the lungs were divided into two parts. The two right lower lobes were used for measurement of the number, length, and diameter of the fibres. The left and remaining right lobes were used to estimate the silicon content of lung tissue by chemical analysis. One of the rats killed after one day was used to confirm that fibres were deposited in the alveolar region of the lung. Parts of the left lung of rats killed after six months were prepared for histopathological examination.

\section{INHALED CERAMIC FIBRES AT THE ALVEOLAR REGION}

The lung of one rat killed after one day was fixed in $2.5 \%$ glutaraldehyde solution, dehydrated in graded acetone/water mixture, and freeze-dried. A section was put on to a scanning electron microscope stub, sputter coated with platinum, and examined for the presence of fibres in the alveolar region with a scanning electron microscope (model S-700, Hitachi, Japan).

\section{DETERMINATION OF CERAMIC FIBRES} RETAINED IN RAT LUNG

Ceramic fibres were extracted on to a $0.2 \mu \mathrm{m}$ pore sized filter (Nuclepore Corp) from the two right lower lobes by low temperature ashing (LAT-25N Yanaco, Japan). ${ }^{10}$ The number, length, and diameter of fibres were determined with a scanning electron microscope according to the reference method for measuring airborne man made mineral fibres proposed by the World Health Organisation (WHO). ${ }^{13}$ The filters were dried, cut, and put on to scanning electron microscope stubs. They were sputter coated with platinum and examined by scanning electron microscopy. Photomicrographs of the filters were taken randomly at a fixed magnification $(\times 2000)$. If any of the fibres had only one end within the field of view, a second photomicrograph was recorded at lower magnification $(\times 1000)$ and centred on the original field so that the fibre length could be assessed. Only particles with aspect ratios $\geqslant 3: 1$ were identified as fibres and these were counted and measured on enlargements $(25 \times 28 \mathrm{~cm})$. To determine the number of ceramic fibres, we counted 1.0 for fibres with two ends in the photographs and 0.5 for fibres with one end. The numbers retained in each rat were calculated on the basis of the reference method of WHO ${ }^{13}$ The fibre sizes were measured on the photographs with a backlight digitiser (KD3030L Graphtec, Japan). The size distributions of inhaled ceramic fibres were calculated for all rats at each time period.

\section{SURFACE STRUCTURE OF CERAMIC FIBRES AT} HIGH MAGNIFICATION

To observe the surface structure of ceramic fibres in rat lungs, some fibres recovered after six months were investigated at high magnification ( $\times 80000)$ by scanning electron microscopy (model S-900, Hitachi, Japan) without sputtering with platinum. Fibres recovered from the mixture of the original material and homogenised lung tissue by low temperature ashing were compared.

\section{SILICON CONTENT OF LUNGS}

The lungs were freeze dried for 24 hours and ashed at low temperature for 24 hours. The samples of ash were fused with sodium carbonate in a platinum crucible and the silicon content measured by absorptiometry. ${ }^{14}$

\section{Results}

DEPOSITION OF FIBRES AT THE ALVEOLAR REGION

Figure 1 shows ceramic fibres in the alveolar region one day after the termination of exposure. Ceramic fibres more than $50 \mu \mathrm{m}$ in length were seen in this region.

\section{NUMBERS OF RESIDUAL CERAMIC FIBRES IN RAT LUNG}

Figure 2 shows scanning electron microphotographs of the ceramic fibres recovered

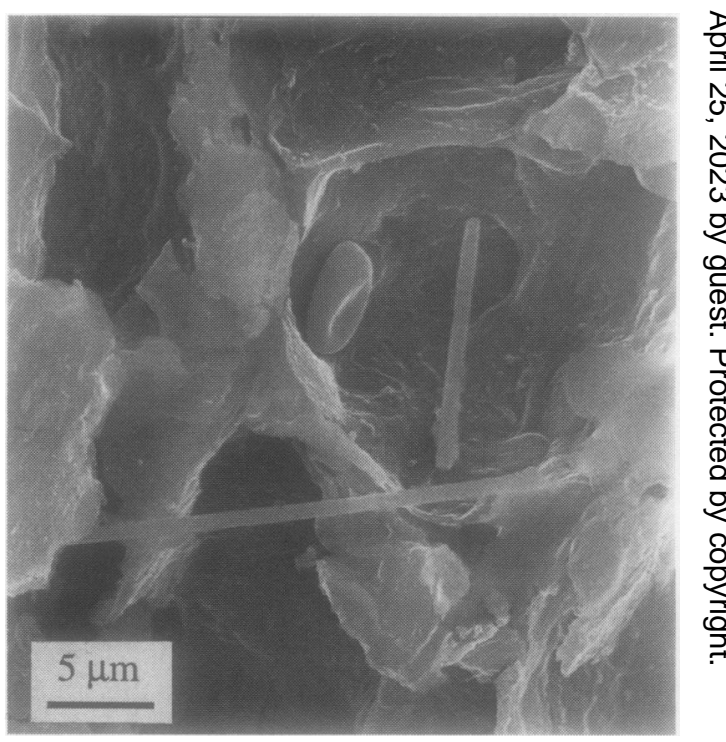

Figure 1 Ceramic fibres in the alveolar region. 
Figure 2 Ceramic fibres recovered on to filters at three months (lefi) and six months (right) after exposure.
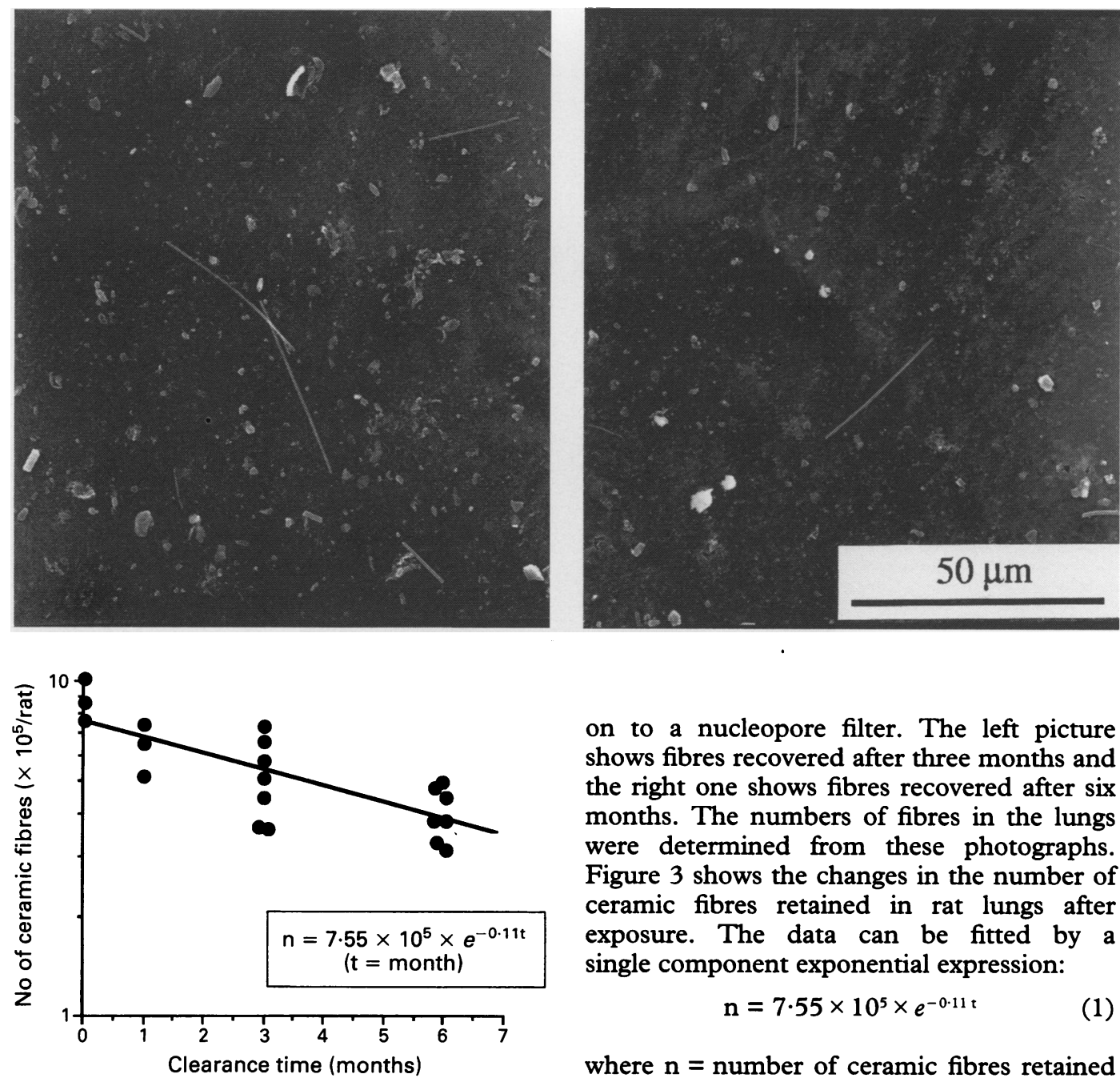

Table Number, diameter, and length of inhaled ceramic fibres recovered from the rat

lung

Changes in retained in rat lungs exposure.

\begin{tabular}{lllll}
\hline $\begin{array}{l}\text { Clearance } \\
\text { time }\end{array}$ & $\begin{array}{l}\text { Number of } \\
\text { rats }\end{array}$ & $\begin{array}{l}\text { Number of CF } \\
\left(10^{5} / \text { rat }\right)\end{array}$ & $\begin{array}{l}\text { GMD (GSD) } \\
(\mu m)\end{array}$ & $\begin{array}{l}\text { GML (GSD) } \\
(\mu m)\end{array}$ \\
\hline 1 day & 3 & $8 \cdot 7(1 \cdot 3)$ & $0.65(1 \cdot 4)$ & $9 \cdot 0(2 \cdot 9)$ \\
1 month & 3 & $6 \cdot 3(1 \cdot 1)$ & $0.63(1 \cdot 5)$ & $9 \cdot 5(3 \cdot 2)$ \\
3 months & 7 & $5 \cdot 2(1 \cdot 4)$ & $0.56^{\star}(1 \cdot 5)$ & $8 \cdot 6(3 \cdot 1)$ \\
6 months & 7 & $4 \cdot 0(0 \cdot 7)^{\star}$ & $0.50^{\star}(1 \cdot 7)$ & $7 \cdot 1(3.0)$ \\
\hline
\end{tabular}

${ }^{\star} \mathrm{p}<0.01 v$ values of one day after the exposure.

$\mathrm{GMD}=$ Geometric median diameter; $\mathrm{GML}$ = geometric median length; $\mathrm{GSD}=$ geometric standard deviation; $\mathrm{CF}=$ ceramic fibres. The values of the number of ceramic fibres retained in each rat were means (SD). Statistical comparisons of the change of fibre number, fibre length, and diameter among each clearance period were analysed by two sample $t$ test. The data for length and diameter were compared after log transformation. on to a nucleopore filter. The left picture shows fibres recovered after three months and the right one shows fibres recovered after six months. The numbers of fibres in the lungs were determined from these photographs. Figure 3 shows the changes in the number of ceramic fibres retained in rat lungs after exposure. The data can be fitted by a single component exponential expression:

$$
\mathrm{n}=7.55 \times 10^{5} \times e^{-0.11 \mathrm{t}}
$$

where $\mathbf{n}=$ number of ceramic fibres retained in the rat lung; $t=$ clearance period (in months)

The solid line in fig 3 shows the calculated clearance rate of the fibre number from equation (1). The decrease in the number of ceramic fibres retained in the rat lung at six months was statistically significant compared with that at one day $(\mathrm{p}<0.01 ; t$ test $)$. The table summarises the result of the change in number. In our previous study, there was a decrease in the number of fibres with time but the change was not significant. A possible explanation for this difference was the larger
Figure 4 Distribution of fibre diameter and fibre length after one day $(\mathbf{x})$, one month $(\bullet)$, three months $(\square)$, and six months $(O)$ clearance time.
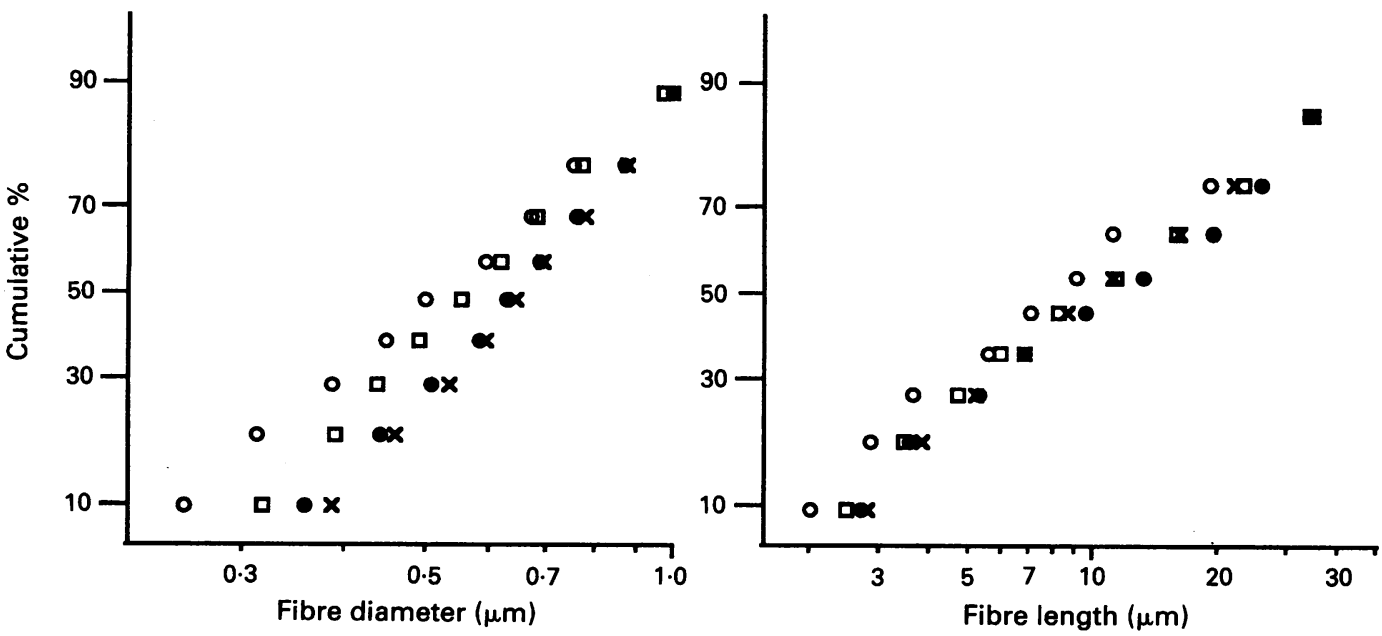
Figure 5 Surface structure of a control fibre (lefi) and a fibre recovered months (right). from a rat lung at six
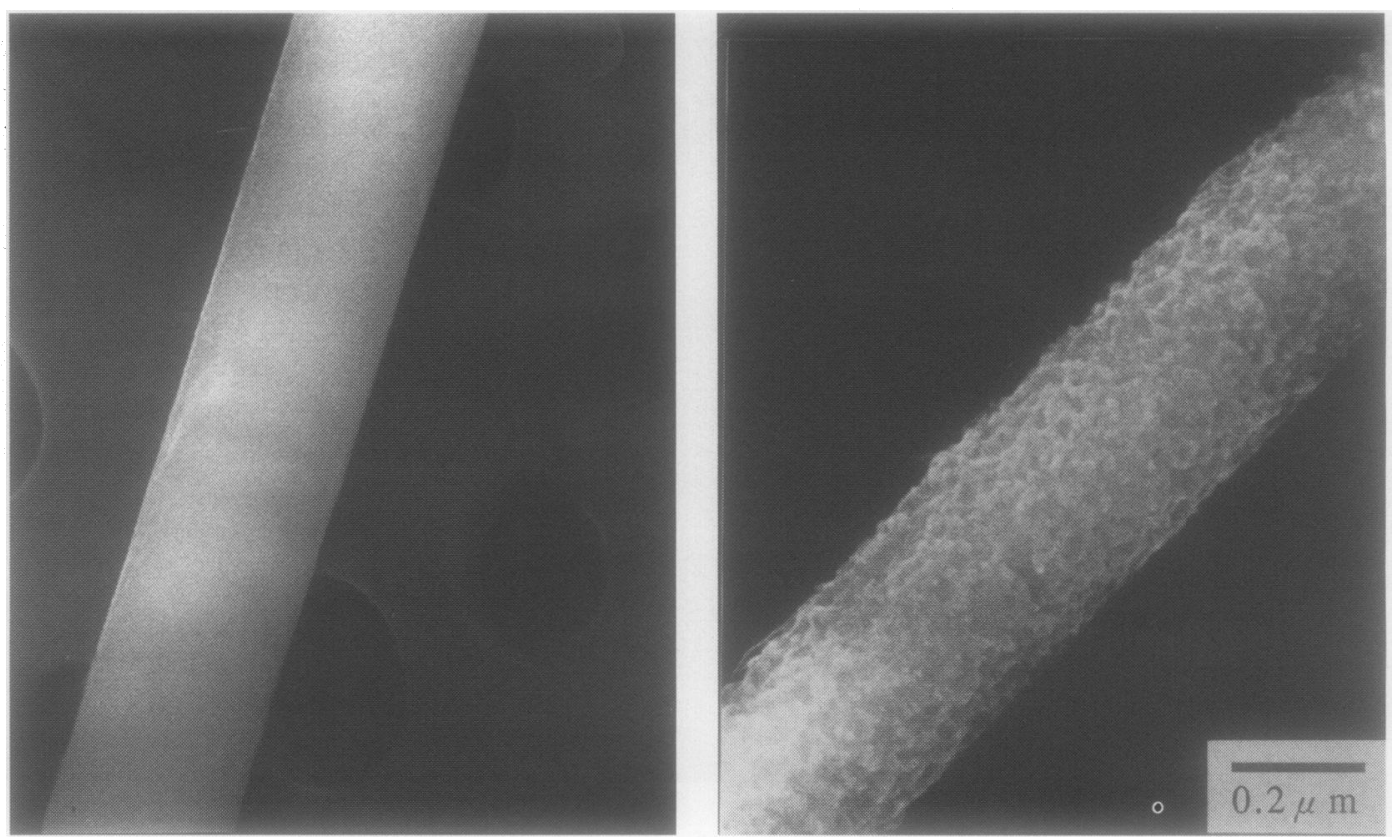

number of rats used in the present study (three to seven rats instead of three to four).

\section{DISTRIBUTION OF FIBRE DIAMETER AND LENGTH}

The size distributions of recovered fibres were assessed at each time period. Both diameter and length could be fitted by log normal distributions as shown in fig 4 . The diameter distribution shifted from right to left during the clearance period corresponding to a reduction in diameters. The change in fibre length was minimal during the first three months followed by a slight decrease after six months. The geometric median length and diameter of the fibres were assessed graphically. The table summarises the results.

\section{SURFACE STRUCTURE OF CERAMIC FIBRES AT HIGH MAGNIFICATION}

Figure 5 shows the change in surface structure of ceramic fibres taken at high magnification ( $\times 80000$ ). Fig 5 (left) shows a control fibre treated by low temperature ashing. Its surface is smooth and the low temperature ashing treatment had no apparent effect on surface structure. Fig 5 (right) shows the surface of a fibre recovered from rat lung at six months. This has an eroded appearance that could not be detected at low magnification.

Figure 6 Mass of retained ceramic fibres estimated from the measurement of the silicon content of rat lungs.
This change in surface characteristics is considered to be due to dissolution.

SILICON CONTENT IN RAT LUNG

Figure 6 shows the mass of retained ceramic fibres estimated from the measurement of the silicon content of rat lungs. The values were corrected for the amount of silicon found in the lungs of control rats and the percentage of $\mathrm{SiO}_{2}(54 \%)$ in the ceramic fibre.

\section{HISTOPATHOLOGICAL FINDINGS}

After six months, parts of the lungs of exposed and control rats were prepared for histopathological examination. No granulomatous response, fibrotic changes, or carcinoma were found either in exposed or control rats. To make a detailed investigation of the pathogenic response to the inhaled ceramic fibres would have required a longer exposure period and an extended study.

\section{Discussion}

CHANGES IN FIBRE NUMBERS AND LENGTH

The numbers of ceramic fibres retained in the lung decreased exponentially (fig 3). A decrease in numbers of fibres after intratracheal injection ${ }^{1-3}$ and inhalation ${ }^{5}$ has been reported previously. The studies showed that short mineral fibres (less than $10 \mu \mathrm{m}$ in length) are cleared from the lung rapidly during the first few months and that the remainder were cleared much more slowly. The geometric median length of ceramic fibre used in the present study was $9.0 \mu \mathrm{m}$ at one day after exposure, which is in the range of short fibres used by Morgan et al ( 5 and 10 $\mu \mathrm{m})^{1}$ and by Le Bouffant et al. ${ }^{5}$ Our study showed that the number of ceramic fibres present in the lung initially decreased to $46 \%$ during the next six months. This result was also in good agreement with that obtained by Morgan et $a l^{1}$ and by Le Bouffant et $a l^{5}$ and is assumed to be the result of macrophage

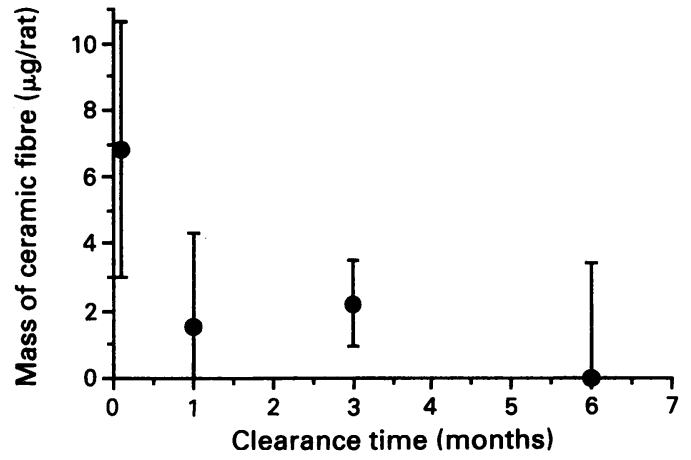


Figure 7 Decrease of geometric mean diameter of ceramic fibres with clearance time.

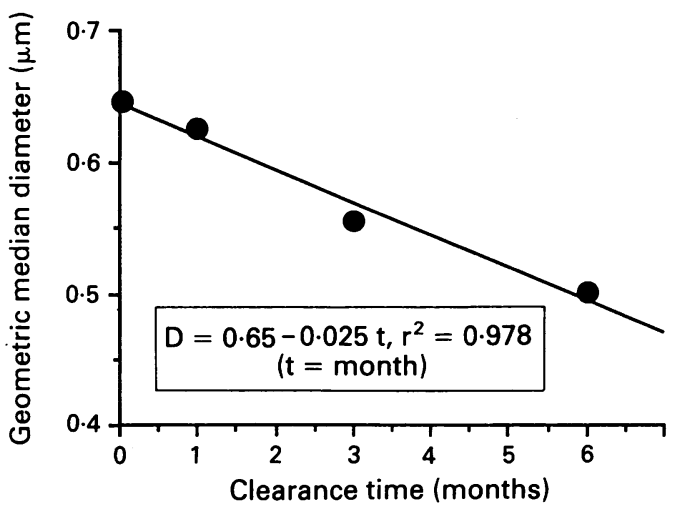

mediated clearance. If short fibres are cleared preferentially, then the geometric median length should increase slightly as reported by Holmes et al. ${ }^{2}$ In our study, however, it seemed that the geometric median length did not change or even decreased slightly. It is not clear whether this was due to the fragmentation of the fibre or not. Further experiments with longer fibres would be required to investigate this point.

\section{CHANGE OF DIAMETER AND THEORETICAL} MODEL OF FIBRE DISSOLUTION

As shown in fig 4, the diameter of recovered ceramic fibres decreased with time due to erosion of the fibre surface. The following theoretical model of fibre dissolution is proposed on the assumption of the following conditions: (1) The fibre is a long and thin column; (2) the fibre length is constant. This experiment proved this point; (3) the dissolution of fibres occurs at their surface and the rate of fibre dissolution is proportional to the surface area. The decrease of volume is described by

$$
-\mathrm{d} \frac{\frac{\left(\pi \mathrm{D}^{2} \mathrm{~L}\right)}{4}}{\mathrm{dt}}=\mathrm{k}\left(\pi \mathrm{DL}+\frac{2 \pi \mathrm{D}^{2}}{4}\right) \cong \mathrm{k} \pi \mathrm{DL}
$$

where $\mathrm{D}=$ fibre diameter $(\mu \mathrm{m}) ; \mathrm{L}=$ fibre length $(\mu \mathrm{m}) ; \mathrm{k}=$ constant of rate of dissolution ( $\mu \mathrm{m} / \mathrm{month})$.

The equation can be rearranged to:

$$
-\frac{\mathrm{dD}^{2}}{\mathrm{dt}}=4 \mathrm{kD}
$$

On integration, equation (3) becomes:

$$
\mathrm{D}=\mathrm{D}_{0}-2 \mathrm{kt}=\mathrm{D}_{0}-\mathrm{Kt}
$$

where $D_{0}=$ the initial diameter of fibre $(\mu \mathrm{m})$; $\mathrm{K}=$ constant of dissolution rate $(\mu \mathrm{m} / \mathrm{month})$.

Equation (4) shows that the fibre diameter decreased linearly with time after exposure. Figure 7 shows the relation between the clearance period and the temporal change in the geometric median diameters. The solid line in this figure shows the regression line based on the equation (4). The decreasing rate of geometric median diameter can be expressed as:

$$
\mathrm{D}=0.65-0.025 \mathrm{t}
$$

The regression line obtained by the equation (4) and the geometric median diameter were in good agreement $\left(r^{2}=0.978\right)$ which means that the assumptions are reasonable. This linear decrease of geometric median diameter was also found in our previous study. ${ }^{10}$

Morgan et al ${ }^{1}$ injected sized glass fibres in rats and measured the dimensions of fibres extracted from the lung. They showed that there was a reduction in the diameter and an increase of the GSD of fibres recovered from the rat lung, and that the effect was more pronounced with long fibres. We plotted the geometric median diameters shown in their table, and found that they decreased almost linearly with the duration of the clearance period. Holmes et $a l^{2}$ gave sized glass fibres to hamsters by intratracheal injection and showed that they dissolved more rapidly in the hamster lung than in the rat lung. They also showed an almost linear decrease of the geometric median diameter in their figure and reported an increase in the GSD. Although there might be a difference in physiological $\mathrm{pH}$ between the animal species (rat and hamster) or between the inside and outside of pulmonary cells in the lung, the linear decrease in the geometric median diameter could be explained by the equations which are shown in this paper. As for the increase in the geometric standard deviation, it can be also explained by the dissolution of fibres. In such cases, the relative decrease in the diameter of thinner fibres is greater than that of thicker ones. Leineweber ${ }^{6}$ has studied the solubility of man made mineral fibres (four types of glass fibres, refractory fibre, and mineral wool) in vitro using water and physiological saline. He found that the square root of the weight of fibre decreased linearly with the time of leaching. The equation developed by Leinweber and our equation (4) are essentially identical.

This phenomenon is important in another way. According to the Stanton-Pott hypothesis, ${ }^{1516}$ the fibres longer than $8 \mu \mathrm{m}$ and thinner than $0.25 \mu \mathrm{m}$ have high carcinogenic potential. Even although the original diameters of inhaled mineral fibres are thicker than Stanton fibres, they could assume the dimensions of Stanton fibres by dissolution in the process of time.

The differential dissolution rates between short and long fibres showed by Morgan and Holmes, ${ }^{7}$ was not confirmed in this study because we used only one type of ceramic fibre. It is necessary to give both long and short ceramic fibres to define whether there are differential dissolution rates or not.

\section{RESIDUAL MASS OF FIBRE CALCULATED FROM}

\section{LENGTH AND DIAMETER}

Because the numbers and dimensions of retained fibres were known for each rat, the mass of residual ceramic fibres could be calculated from fibre density $\left(\rho=2.5 \mathrm{~g} / \mathrm{cm}^{3}\right)$. The results are shown in fig 8 , from which it can be seen that there was a difference between the values of fibre mass obtained in this way and by measuring the silicon content in the lung (see fig 6). One explanation for this discrepancy might be that the mass 
Figure 8 Mass of retained ceramic fibres estimated from fibre density.

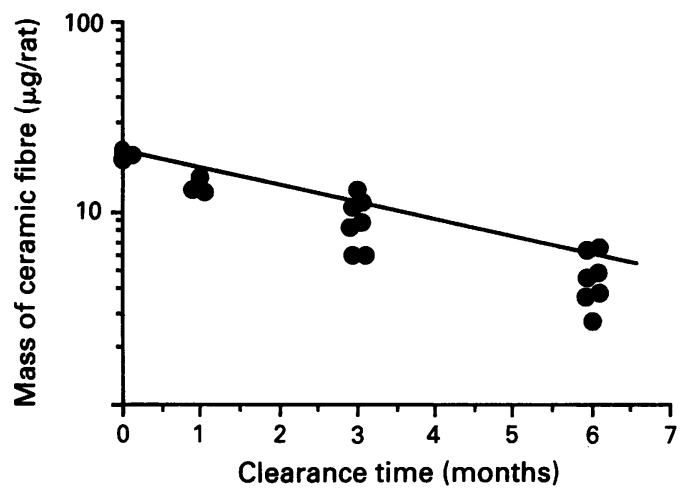

calculated from the fibre volume was assessed only for the fibres that had aspect ratios greater than 3:1, whereas the fibre mass based on silicon analysis applied to all fibres and ceramic fragments.

The decreasing mass of fibres due to their elimination and dissolution can be expressed:

$\%$ of original mass $=$

$$
\frac{M}{M_{0}}=\frac{\sum_{n=1}^{n} D^{2}}{\sum_{n=1} D_{0}^{2}} \times \frac{n}{n_{0}} \times 100
$$

when equations (1) and (5) are substituted for equation (6),

$\%$ of original mass $=$

$$
\frac{\sum_{n=1}^{n}\left(D_{0}-0.025 t\right)^{2}}{\sum_{n=1}^{n_{0}} D_{0}^{2}} \times e^{-0.11 t} \times 100
$$

The mass of retained fibre can be calculated from equation (7) and was $82.5 \%$ after one month, $55.7 \%$ after three months, and $30.0 \%$ after six months. Taking the initial mass of fibre as $20.2 \mu \mathrm{g} / \mathrm{rat}$, (the average value at one day), the calculated rate is shown in fig 8 as a solid line. The experimental data and calculated line are in good agreement.

CHANGE OF SURFACE STRUCTURE

As shown in fig 5 , the ceramic fibres had an eroded appearance. Le Bouffant et $a l^{5}$ also showed that fibres that had remained for several months in the rat lung had an eroded appearance whereas the original fibres had a smooth surface. Leineweber ${ }^{6}$ showed that solvent attack on fibres in vitro was accompanied by the build up of a crust or shell and demonstrated that the degree of surface change depended on the fibre's solubility. In this study, we used a ceramic fibre that is considered to be only slightly soluble in vivo (unpublished data). No surface change was seen at lower magnifications, but at higher magnifications the eroded appearance of the fibre surface was evident. It was concluded that the examination of fibres that are resis- tant to dissolution must be performed at high magnification. Also, the observation of resistant fibres at high magnifications must be performed without sputter coating because the particles of sputtering material interfere with the fine surface structure.

\section{Conclusions}

(1) The number of initially retained ceramic fibres decreased exponentially according to the duration of the clearance period.

(2) The geometric median diameter decreased linearly with time.

(3) The surface of fibres recovered after six months had an eroded appearance.

(4) The clearance of inhaled ceramic fibre (geometric median length $9.0 \mu \mathrm{m}$, geometric median diameter $0.65 \mu \mathrm{m}$ ) was mediated through dissolution and macrophage mediated clearance.

(5) The clearance rate of inhaled fibre can be calculated by measuring the number, dimension, and dissolution rate of fibres in the lung.

We thank Ms S Ishimatsu and Ms T Oyabu for their excellent technical help.

1 Morgan A, Holmes A, Davison W. Clearance of sized glass fibres from the rat lung and their solubility in vivo. Ann Occup Hyg 1982;25:317-31.

2 Holmes A, Morgan A, Davison W. Formation of pseudoasbestos bodies on sized glass fibres in the hamster lung. Ann Occup Hyg 1983;27:301-13.

3 Bellmann B, Muhle H, Pott F, Konig H, Kloppel H, Spurny K. Persistence of man-made mineral fibres (MMMF) and asbestos in rat lungs. Ann Occup Hyg 1987;31:693-709.

4 Tanaka I, Akiyama T. Pulmonary deposition fraction of a glass fiber in rats by inhalation. In: Masuda $S$, glass fiber in rats by inhalation. In: Masuda S, environment. Oxford: Pergamon Press, 1990;1 242-5.

5 Le Bouffant L, Daniel H, Henin JP, Martin JC, Normand C, Tichoux G, Trolard F. Experimental study on longterm effects of inhaled MMMF on the lungs of rats. Ann Occup Hyg 1987;31:765-90.

6 Leineweber JP. Solubility of fibres in vitro and in vivo. In: Proceedings of World Health Organisation/International Agency for Research on Cancer conference. Biological effects of man-made mineral fibres. Copenhagen: WHO $1984 ; 87-101$.

7 Morgan A, Holmes A. Solubility of asbestos and manmade mineral fibers in vitro and in vivo: its significance in lung disease. Environ Res 1986;39:475-84.

8 Tanaka I, Akiyama T. A new dust generator for inhalation toxicity studies. Ann Occup Hyg 1984;28:157-62.

9 Tanaka I, Akiyama T. Fibrous particles generator for inhalationtoxicity studies. Ann Occup Hyg 1987;31: 401-3

10 Yamato H, Tanaka I, Higashi T, Kido M. Determinant factor for clearance of ceramic fibres from rat lungs. Br F Ind Med 1992;49:182-5.

11 Yamato $H$, Hori $H$, Tanaka $I$, Higashi $T$, Kido $M$. Clearance of inhaled ceramic fibers and its dissolution model. In: Gibbs WG, Kido M, Dunnigan J, Higashi T, eds. eds. Health risks from exposure to mineral fibers. an inter1993;273-80.

12 Yamato $H$, Tanaka I, Higashi T, Kido M. Clearance of inhaled ceramic fibers from rat lungs. Environ Health Perspect 1994 (in press)

13 World Health Organization. Reference methods for measuring airborme man-made mineral fibres (MMMF). Copenhagen: WHO, Regional Office for Europe. 1985:36-54. (Environmental health report No 4.)

4 King EJ, Stacy BD. The colorimetrical determination of silicon in the micro-analysis of biological material and mineral dusts. Analyst 1955;80:441-5

15 Stanton MF, Layard M, Tegeris A, Miller E, May M, Kent E. Carcinogenicity of fibrous glass: Pleural response in the rat in relation to fiber dimension. $\mathcal{F}$ Natl Cancer Inst 1977;58:587-603.

16 Pott F, Huth F, Friedrichs $\mathrm{KH}$. Tumorigenic effect of fibrous dusts in experimental animals. Environ Health Perspect 1974;:9:313-5. 